\title{
The clinicopathological significance of CDHI in gastric cancer: a meta-analysis and systematic review
}

This article was published in the following Dove Press journal:

Drug Design, Development and Therapy

I 3 April 2015

Number of times this article has been viewed

\author{
Wei Zeng ${ }^{1,2, *}$ \\ Jinfeng $\mathrm{Zhu}^{3, *}$ \\ Li Shan ${ }^{2}$ \\ Zhigang $\mathrm{Han}^{2}$ \\ Patiguli Aerxiding ${ }^{2}$ \\ Amina Quhai ${ }^{2}$ \\ Fanye Zeng ${ }^{4}$ \\ Ziwei Wang ${ }^{5}$ \\ Huiwu Li ${ }^{6}$ \\ 'College of Public Health, Xinjiang \\ Medical University, Xinjiang, People's \\ Republic of China; ${ }^{2}$ First Department \\ of Lung Cancer Chemotherapy, The \\ Affiliated Cancer Hospital of Xinjiang \\ Medical University, Xinjiang, People's \\ Republic of China; ${ }^{3}$ Department \\ of Gastrointestinal Surgery, The \\ Affiliated Cancer Hospital of Xinjiang \\ Medical University, Xinjiang, People's \\ Republic of China; ${ }^{4}$ Department \\ of Oncology, Traditional Chinese \\ Medical Hospital Affiliated to Xinjiang \\ Medical University, Xinjiang, People's \\ Republic of China; ${ }^{5}$ Department \\ of Gastrointestinal Surgery, First \\ Affiliated Hospital of Chongqing \\ Medical University, Chongqing, \\ People's Republic of China; ${ }^{6}$ School \\ of Basic Medicine, Xinjiang Medical \\ University, Xinjiang, People's Republic \\ of China
}

*These authors contributed equally to this work

Correspondence: Huiwu Li School of Basic Medicine, Xinjiang Medical University, No 393, Xinyi Road, Urumqi, Xinjiang 8300 I I, People's Republic of China

$\mathrm{Tel}+86$ 991 7819910

Email huiwulimd@yeah.net
Background: $\mathrm{CDH} 1$ is a protein encoded by the $\mathrm{CDH} 1$ gene in humans. Loss of $\mathrm{CDH} 1$ function contributes to cancer progression by increasing proliferation, invasion, and/or metastasis. However, the association and clinicopathological significance between $C D H 1$ hypermethylation and gastric cancer (GC) remains unclear. In this study, we systematically reviewed the studies of $C D H 1$ hypermethylation and $\mathrm{GC}$, and evaluated the association between $\mathrm{CDH} 1$ hypermethylation and GC using meta-analysis methods.

Methods: A comprehensive search of the PubMed and Embase databases was performed for publications up to July 2014. Methodological quality of the studies was also evaluated. The data were extracted and assessed by two reviewers independently. Analyses of pooled data were performed. Odds ratios (ORs) were calculated and summarized.

Results: A final analysis of 1,079 GC patients from 14 eligible studies was performed. $C D H 1$ hypermethylation level in the cancer group was significantly higher compared to the normal gastric mucosa (OR $=8.55,95 \%$ confidence interval $[\mathrm{CI}]: 2.39-33.51, Z=5.47$, $P<0.00001)$. $C D H 1$ hypermethylation was not significantly higher in GC than in adjacent gastric mucosa $(\mathrm{OR}=3.68,95 \% \mathrm{CI}$ : 0.96-14.18, $Z=1.90, P=0.06)$. However, $C D H 1$ hypermethylation was higher in adjacent gastric mucosa compared to that in normal gastric mucosa (OR $=2.55,95 \% \mathrm{CI}: 1.22-5.32, Z=2.49, P<0.01)$. In addition, $C D H 1$ hypermethylation was correlated with Helicobacter pylori (HP) status in GC. The pooled OR from six studies including 280 HP-positive GCs and 193 HP-negative GCs is 1.72 (95\% CI: 1.13-2.61, $Z=2.55, P=0.01)$.

Conclusion: The results of this meta-analysis reveal that $C D H 1$ hypermethylation levels in cancer and adjacent gastric mucosa are significantly higher compared to normal gastric mucosa. Thus, $C D H 1$ hypermethylation is significantly correlated with GC risk. $C D H 1$ hypermethylation is correlated with HP status, indicating that it plays a more important role in the pathogenesis of HP-positive GC and might be an interesting potential drug target for GC patients.

Keywords: methylation, tumor suppressor gene, odds ratio

\section{Background}

Stomach cancer, also known as gastric cancer (GC), is the second most common cause of cancer-related death according to the World Health Organization, and 800,000 cancer-related deaths are caused by GC each year globally. ${ }^{1}$ Although diagnostic methods, surgical techniques, targeted therapy, and perioperative care have undergone considerable advancements, GC remains difficult to cure and prognosis remains poor with a median overall survival of 12 months for advanced disease in Western countries. ${ }^{2,3}$ Thus, in order to improve the clinical outcome of GC patients, investigation on the mechanism of incidence and progression of GC, as well as identification 
of new biomarkers and drug targets, are still needed and will help to select patients with high chances of GC recurrence and provide better prognosis and individualized treatments. Aberrant methylation of $\mathrm{CpG}$ dinucleotides is a commonly observed epigenetic modification and plays an important role in the initiation and progression in human cancer. ${ }^{4-6}$ Thus, the analysis of specific gene promoter methylation as a diagnostic and/or prognostic marker has been widely used for many different cancers including GC. ${ }^{7,8}$

Cadherin-1 (CDH1), also known as epithelial cadherin (E-cadherin), CAM 120/80, or uvomorulin, a member of the transmembrane glycoprotein family, is encoded by the $\mathrm{CDH} 1$ gene (16q22.1). ${ }^{9,10} \mathrm{CDH} 1$, a calcium-dependent cell-cell adhesion glycoprotein which contains three domains, ie, five extracellular cadherin repeats, a transmembrane region, and a highly conserved cytoplasmic tail, plays an essential role in maintaining cell adhesion and adherent junction in normal tissues. ${ }^{11} \mathrm{CDH} 1$ expression is frequently inactivated or absent in a variety of epithelial tumors, and loss of normal intercellular junctions results in promoted cancer invasion and metastasis and is correlated with several types of cancers including GC. ${ }^{12-16}$ Although previous studies indicated that inactivation of $C D H 1$ is mainly induced by hypermethylation of the $C D H 1$ gene, the reported rates of $C D H 1$ hypermethylation in GC were remarkably diverse. In addition, the correlation and incidence between $\mathrm{CDH} 1$ promoter hypermethylation and $\mathrm{GC}$ remains unclear. In this study, we systematically investigated studies of $C D H 1$ promoter hypermethylation and $\mathrm{GC}$, and validated the correlation between $C D H 1$ promoter hypermethylation and GC using meta-analysis methods. We will summarize these findings and discuss the tumor suppressor function, as well as the clinicopathological significance of $C D H 1$ in GC.

\section{Methods}

\section{Publication selection}

A systematic literature search was performed using Pubmed, Embase, and Web of Science for publications up to July 15, 2014 without any language restrictions. The following keywords and terms were used: [methylation or DNA methylation or hypermethylation or de-methylation] and [CDH1 or Cadherin-1 or CAM 120/80 or epithelial cadherin (E-cadherin) or uvomorulin] and [gastric cancer or gastric carcinoma or gastric tumor]. Also, references from these publications were manually searched to acquire additional studies. Titles, abstracts, and keywords of the articles were initially evaluated for appropriate purpose. Then, details and additional information were identified and collected from full texts of these articles.

\section{Inclusion and exclusion criteria}

A study included for the meta-analysis needed to meet the following criteria: 1) studies which evaluated the correlation between $\mathrm{CDH} 1$ methylation and $\mathrm{GC} ; 2$ ) the subjects in every study included clinical cohort and case control; 3 ) when the same groups of patients were reported in multiple papers, only the most recent and complete paper was selected to avoid overlap; 4) numbers of patients and controls needed to be larger than three; 5) only the tissue data were selected and the blood data was excluded from the study. If a study did not meet the inclusion criteria, it was excluded.

\section{Data extraction and quality assessment}

Two researchers independently collected the information and extracted the data regarding the authors, year, source of publication, inclusion criteria, $C D H 1$ methylation frequencies, sexual status, smoking history, pathological types, clinical staging, differentiation degree, lymph node metastasis, epidermal growth factor receptor (EGFR) status, and prognostic conditions in patients and control groups. Any discrepancy was adjusted by discussion until they reached an agreement. The data are summarized in Table 1 based on the criteria mentioned above. Methodological evaluation was assessed by two independent researchers according to REMARK guidelines and the European Lung Cancer Working Party quality scale. ${ }^{17,18}$

\section{Data analysis}

Meta-analysis was performed using Reviewer Manager 5 (Cochrane Collaboration, Oxford, UK). The pooled odds ratios (ORs) and confidence intervals (CIs) were calculated to assess the correlation between $C D H 1$ methylation and GC. Cochran's $Q$-test and $I^{2}$ were adopted to assess heterogeneity among studies. ${ }^{19}$ If the $Q$-test showed $P<0.05$ or $I^{2}$ test was $>50 \%$, it indicated significant heterogeneity and a fixed effects model was used to calculate the parameters. Otherwise, a random effects model was used to pool data and attempt to identify potential sources of heterogeneity based on subgroup analyses..$^{20,21}$ "Events" means number of hypermethylation cases. An overall effect is calculated as a weighted average of the individual summary statistics. Greater weights are given to the results from studies that provide more information. The weights are often the inverse of the variance (the square of the standard error) of the methylation rates, which relates closely to sample size. The typical graph for displaying the results of a meta-analysis is called a "forest plot". 


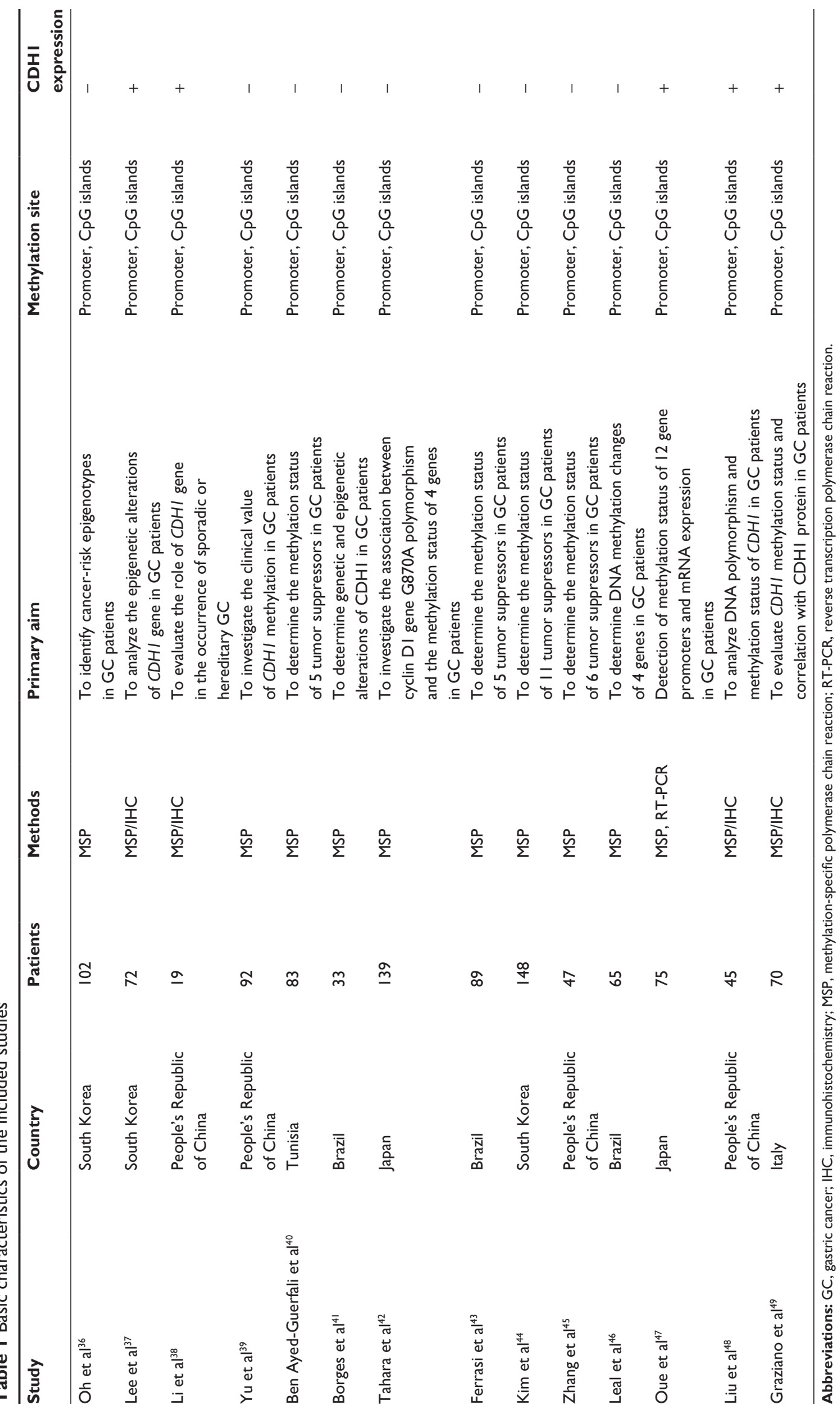


Publication bias was detected by the Begg's test and funnel plots. ${ }^{22}$ The analysis of meta-regression and publication bias were performed using STATA version 10.0.

\section{Results}

The selection process of articles used in this report is shown in Figure 1. Ninety-three articles were searched by electronic database and additional information was sorted manually. Seventy-nine articles were excluded due to duplicated articles, irrelevant title and abstract, laboratory studies, non-original articles (review), or studies irrelevant to the current analysis. Finally, 14 reliable studies published from 2004 to 2014 were screened out based on the inclusion and exclusion criteria in the pooled analysis. A total of 1,079 GC patients from the People's Republic of China, South Korea, Japan, Tunisia, Brazil, and Italy were included. Their basic characteristics are summarized in Table 1.

By analyzing 587 cancer tissues and 389 normal mucosa tissues, the frequency of $\mathrm{CDH} 1$ hypermethylation ranged from $28.6 \%$ to $82.2 \%$ (average $61 \%$ ) in cancer tissues and from $0.00 \%$ to $54.5 \%$ (average $16 \%$ ) in normal mucosa, respectively.
This result indicates that the occurrence of $\mathrm{CDH} 1$ hypermethylation in cancer tissues is higher than in normal mucosa. Under the random model, the meta-analysis result shows that nine studies were pooled OR as shown in Figure 2 (OR $=8.55,95 \%$ CI: $2.39-33.51$, test for overall effect, $Z=5.47$, $P<0.00001)$. These results indicate that $C D H 1$ hypermethylation is the key molecular event in cancer tissue rather than normal mucosa, and the results show the heterogeneity across the included studies ( $I^{2}$ is $64 \%$ which is larger than $50 \%$ ).

Then, we determined whether or not the $C D H 1$ hypermethylation rate in $\mathrm{GC}$ was significantly higher than that in adjacent gastric mucosa. The pooled OR from six studies including $467 \mathrm{GC}$ tissues and 298 adjacent gastric mucosa tissues is shown in Figure 3 (OR $=3.68,95 \%$ CI: 0.96-14.18, $Z=1.90$, $P=0.06$ ), which indicates that $C D H 1$ hypermethylation is not significantly higher in GC than in adjacent gastric mucosa.

We determined whether or not $C D H 1$ hypermethylation was higher in adjacent gastric mucosa compared to that in normal gastric mucosa. There was no evidence of heterogeneity across the studies ( $P$ for heterogeneity $=0.41 ; I^{2}=0 \%$ ). The pooled OR from four studies including 205 adjacent gastric mucosa tissues

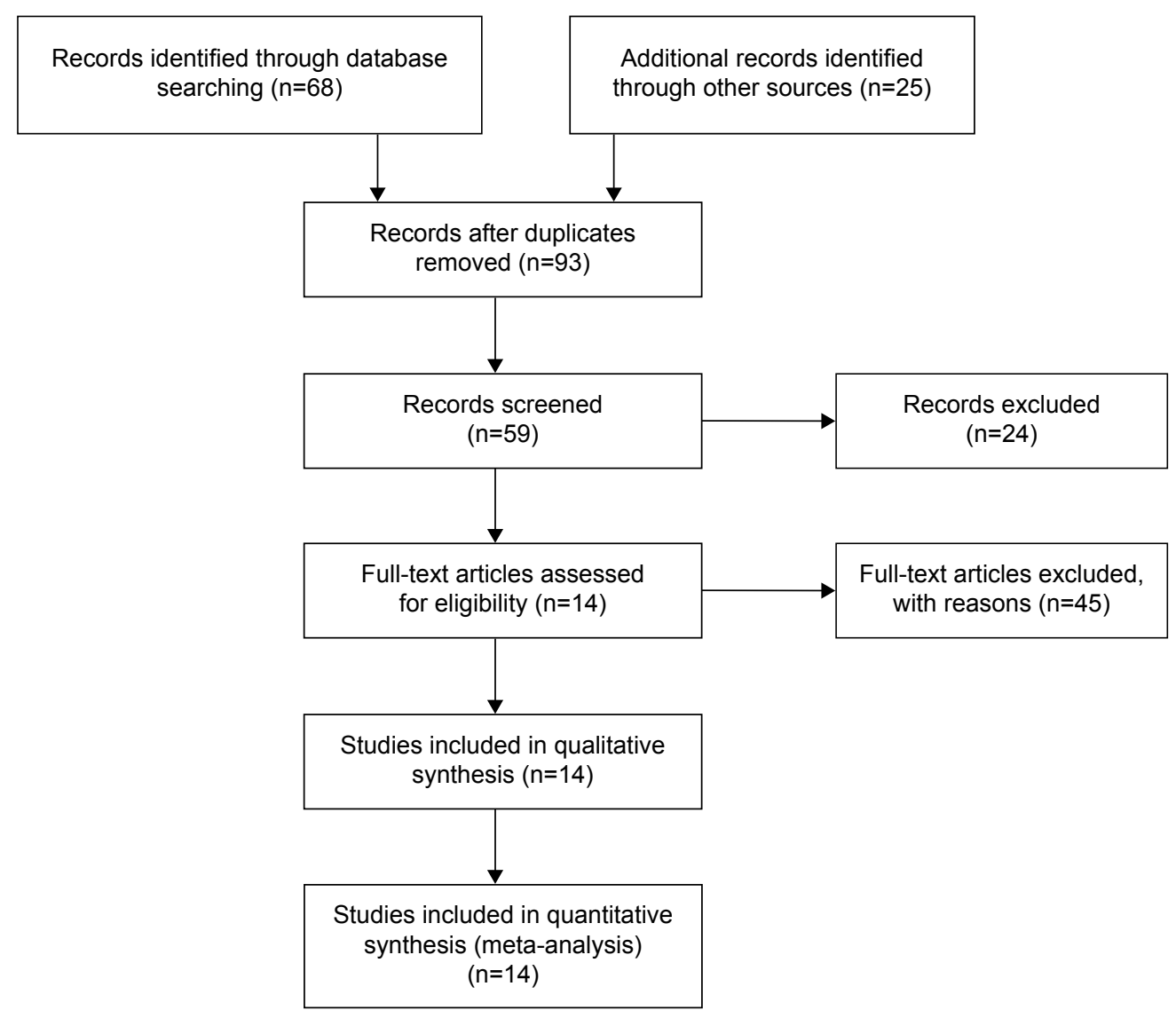

Figure I Flow diagram of the literature search strategy and assessment of studies identified for meta-analysis. 


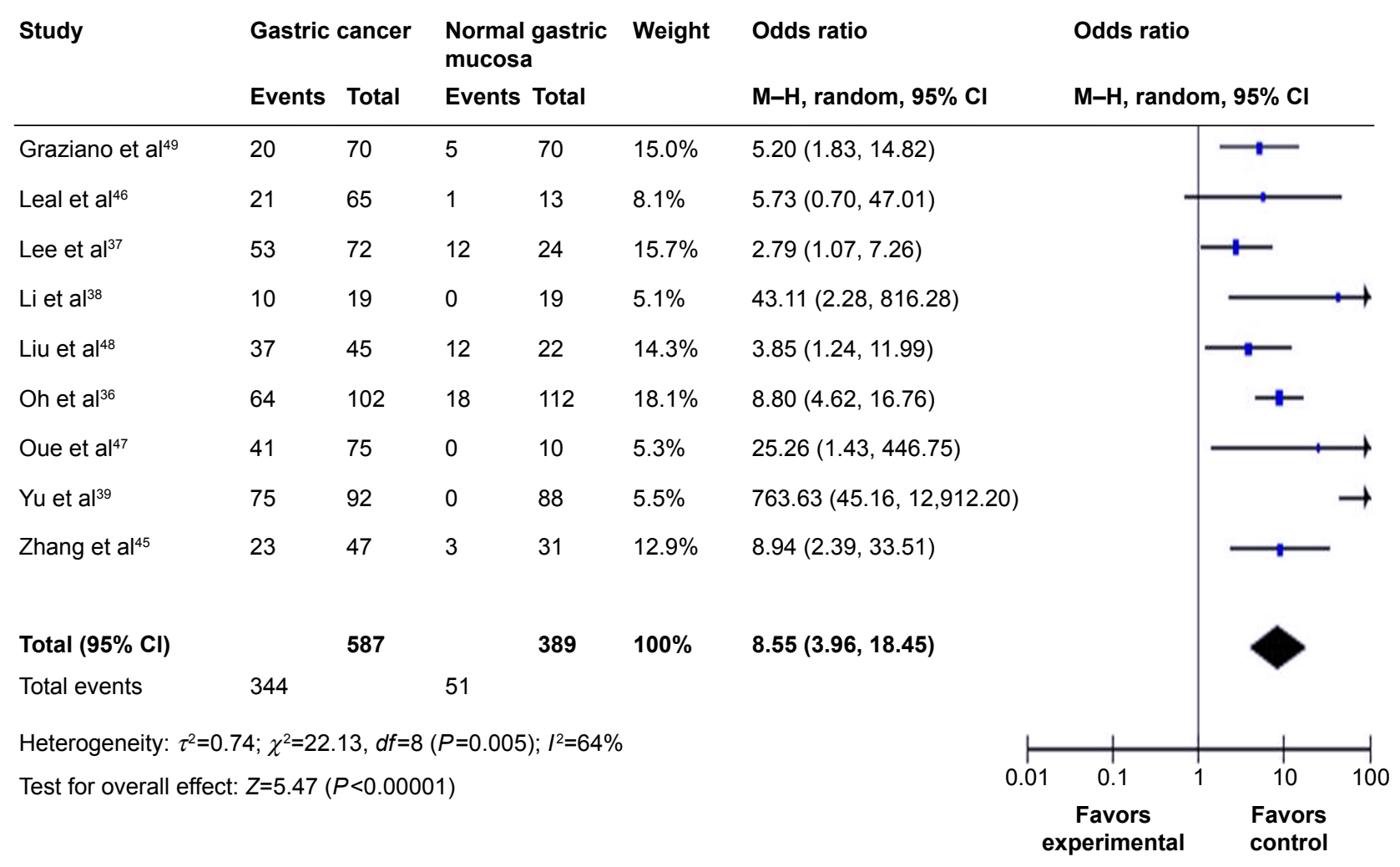

Figure 2 The pooled OR from nine studies including 587 gastric cancer tissues and 389 normal mucosa tissues.

Notes: $O R=8.55,95 \% \mathrm{Cl}: 2.39-33.5 \mathrm{I}$, test for overall effect, $Z=5.47, P<0.0000 \mathrm{I}$.

Abbreviations: $\mathrm{Cl}$, confidence interval; $d f$, degrees of freedom; OR, odds ratio; $\mathrm{M}-\mathrm{H}$, Mantel-Haenszel.

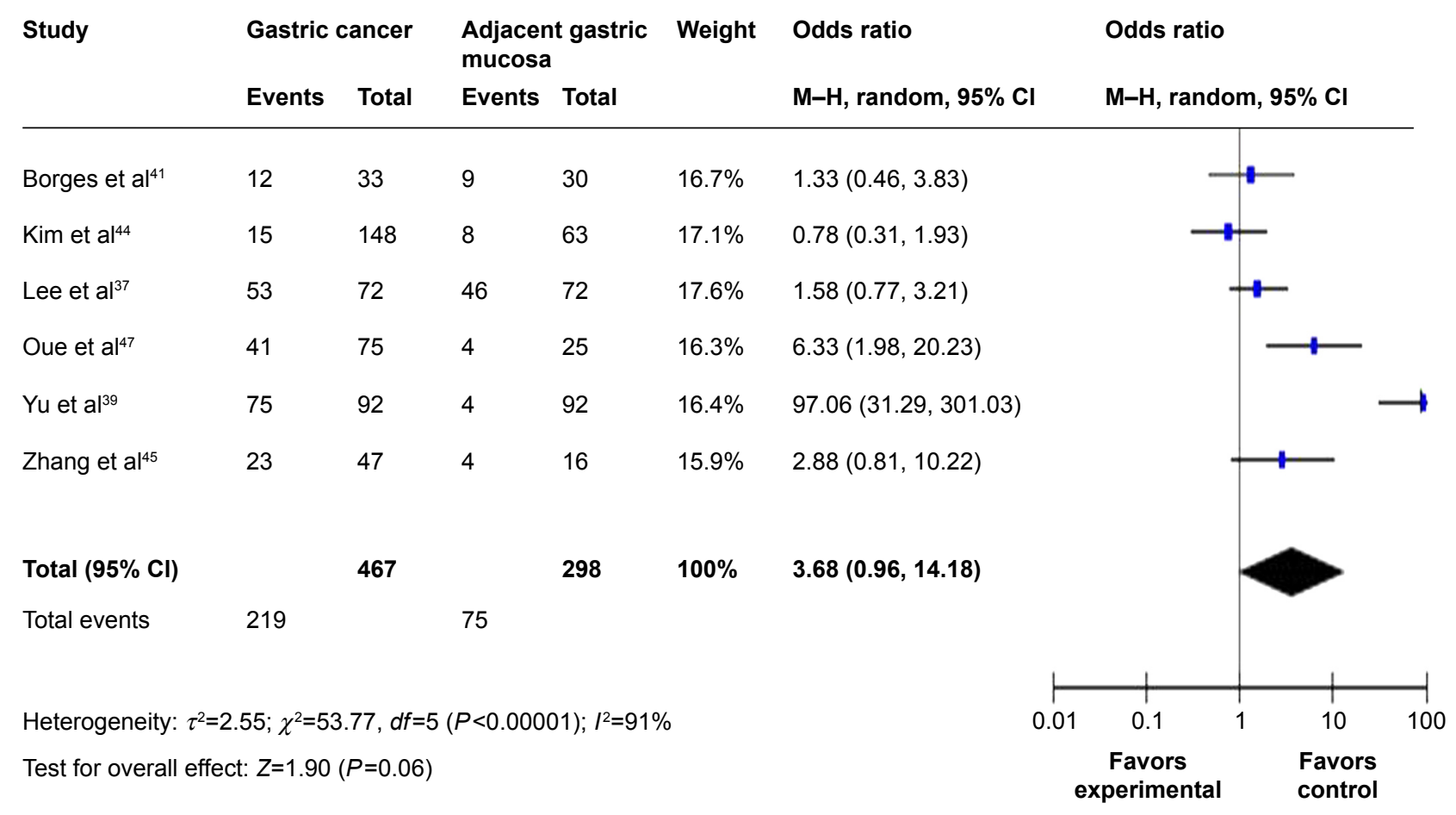

Figure 3 The pooled OR from six studies including 467 gastric cancer tissues and 298 adjacent gastric mucosa tissues. Notes: $O R=3.68,95 \% \mathrm{Cl}: 0.96-14.18, Z=1.90, P=0.06$.

Abbreviations: $\mathrm{Cl}$, confidence interval; $d f$, degrees of freedom; OR, odds ratio; $\mathrm{M}-\mathrm{H}$, Mantel-Haenszel. 
and 153 normal gastric mucosa tissues is shown in Figure 4 (OR $=2.55,95 \%$ CI: 1.22-5.32, $Z=2.49, P<0.01)$, which indicates that $C D H 1$ hypermethylation plays a more important role in the pathogenesis of adjacent gastric mucosa.

Since it was described that DNA hypermethylation was associated with Helicobacter pylori (HP) infection but the mechanisms are not yet identified, ${ }^{23,24}$ we determined whether or not $C D H 1$ hypermethylation was correlated with HP status in GC. The pooled OR from six studies including 280 HP-positive GCs and 193 HP-negative GCs is shown in Figure $5(\mathrm{OR}=1.72,95 \% \mathrm{CI}: 1.13-2.61, Z=2.55, P=0.01)$, which indicates that $C D H 1$ hypermethylation plays a more important role in the pathogenesis of HP-positive GC.

A sensitivity analysis, in which one study was removed at a time, was conducted to assess the result stability. The pooled ORs were not significantly changed, indicating the stability of our analyses. The funnel plots were largely symmetric (Figure 6), suggesting there were no publication biases in the meta-analysis.

\section{Discussion}

DNA methylation is an important epigenetic mechanism for gene expression regulation. The imbalance of gene methylation can induce a variety of human diseases. The hypermethylation of tumor suppressor genes and hypomethylation of oncogenes are two essential components of the molecular mechanism in the gene epigenomic regulation for cancer initiation and progression. $C D H 1$ is genetically or epigenetically altered in many different kinds of primary and advanced carcinomas. Inactivation of $C D H 1$ by promoter hypermethylation plays an important role in tumorigenesis in several types of tumors including GC. ${ }^{25-27}$ To date, there have been some studies describing the methylation status of CDH1 in GC; however, the roles of methylation of $C D H 1$ in GC and clinical significance have not been thoroughly investigated. In this meta-analysis, we mainly focused on the correlation between $C D H 1$ hypermethylation and GC. We analyzed the data from 14 previous scientific articles. The results show that the $C D H 1$ hypermethylation level of the cancer group was significantly higher than in normal gastric mucosa. The total OR is 8.55 (95\% CI: 2.39-33.51, test for overall effect, $Z=5.47, P<0.00001)$. $C D H 1$ hypermethylation plays a key role in the induction of GC due to silencing the tumor suppressor gene $C D H 1$. Analysis of the pooled data also shows that $C D H 1$ hypermethylation was not significantly higher in $\mathrm{GC}$ than in adjacent gastric mucosa $(\mathrm{OR}=3.68$, 95\% CI: 0.96-14.18, $Z=1.90, P=0.06)$. However, $C D H 1$ hypermethylation was higher in adjacent gastric mucosa compared to that in normal gastric mucosa $(\mathrm{OR}=2.55$, 95\% CI: $1.22-5.32, Z=2.49, P<0.01)$. In addition, $C D H 1$ hypermethylation was correlated with HP status in GC. The pooled OR from six studies including $280 \mathrm{HP}$-positive GC and 193 HP-negative GC is 1.72 (95\% CI: 1.13-2.61, $Z=2.55$, $P=0.01)$. The results from the current study demonstrate that the hypermethylation rate of $\mathrm{CDH} 1$ gene promoter in $\mathrm{GC}$ is strongly associated with GC incidence. Since changes

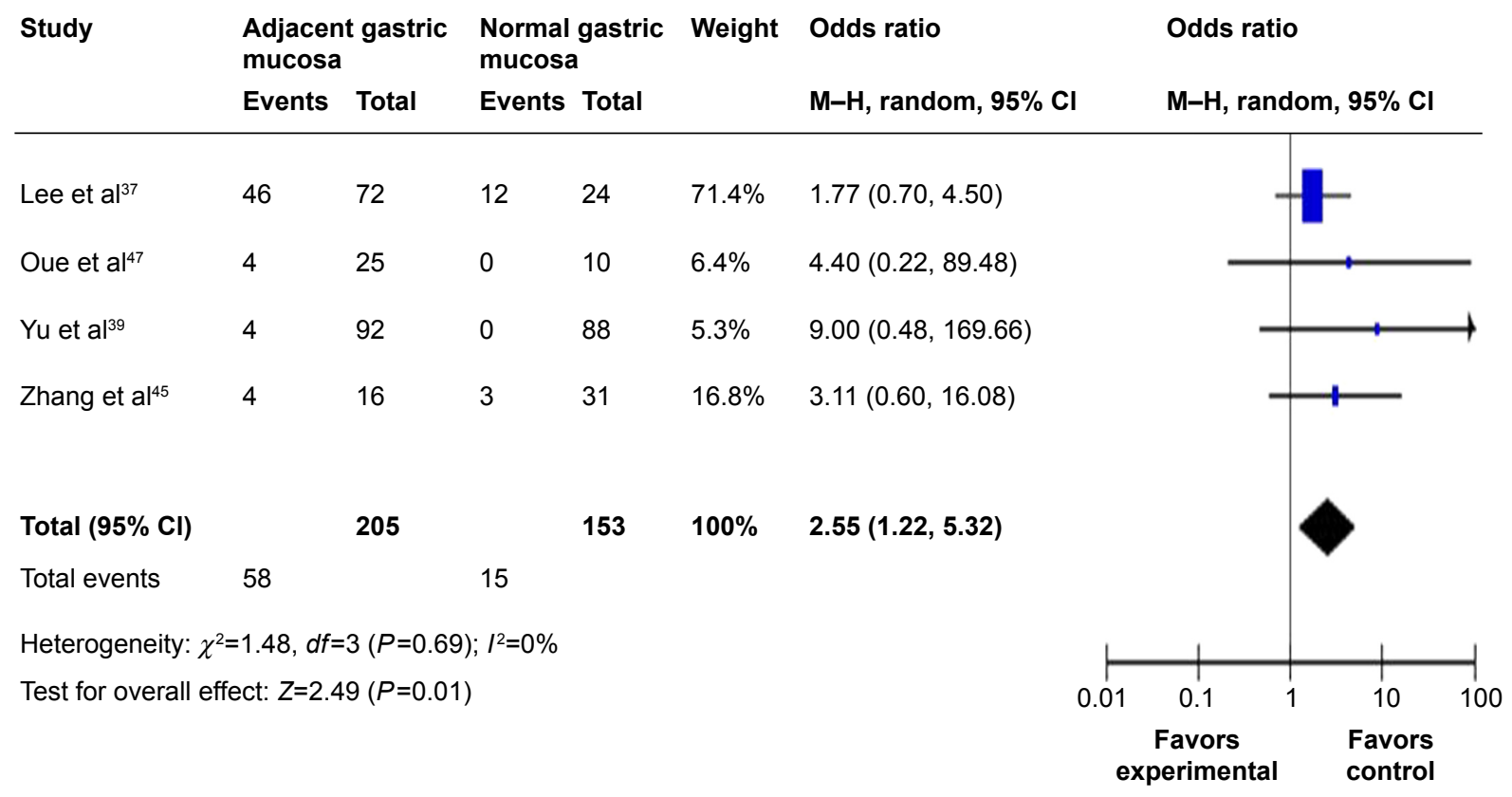

Figure 4 The pooled OR from four studies including 205 adjacent gastric mucosa and I53 normal gastric mucosa tissues. Notes: $O R=2.55,95 \% \mathrm{Cl}$ : $1.22-5.32, Z=2.49, P<0.0$ I.

Abbreviations: $\mathrm{Cl}$, confidence interval; df, degrees of freedom; OR, odds ratio; $\mathrm{M}-\mathrm{H}$, Mantel-Haenszel. 


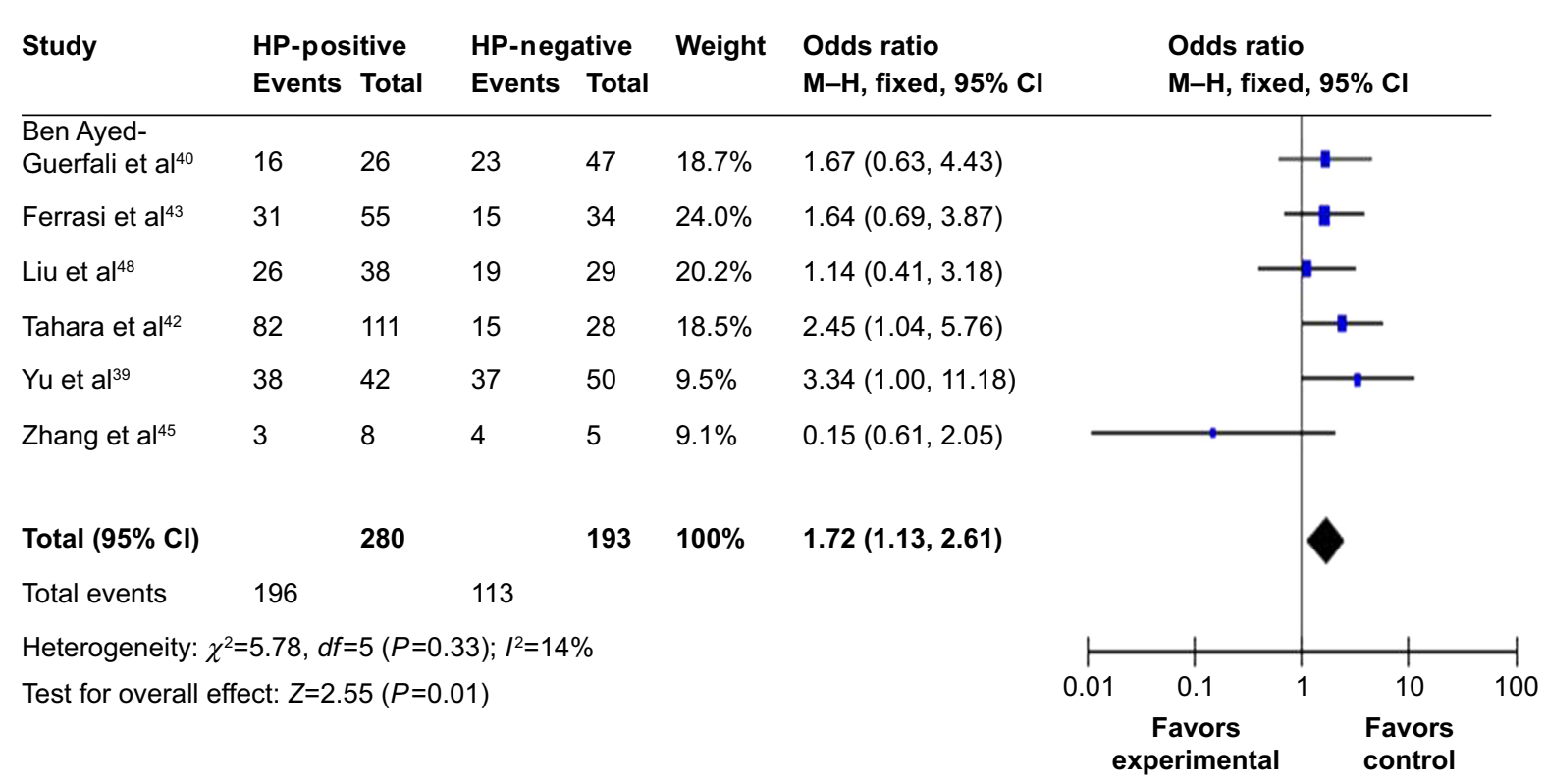

Figure 5 The pooled OR from six studies including $280 \mathrm{HP}$-positive and $193 \mathrm{HP}$-negative gastric cancers.

Notes: $O R=1.72,95 \% \mathrm{Cl}:$ I. $13-2.6 \mathrm{I}, \mathrm{Z}=2.55, P=0.01$.

Abbreviations: $\mathrm{Cl}$, confidence interval; $d f$, degrees of freedom; HP, Helicobacter pylori; OR, odds ratio; M-H, Mantel-Haenszel.

A

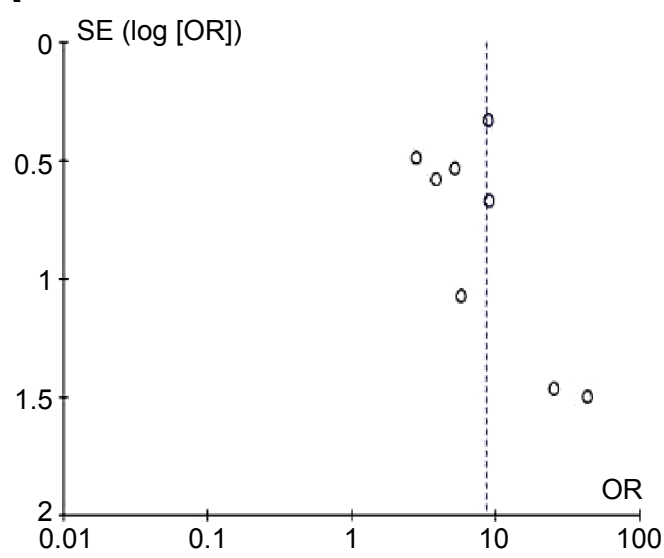

C

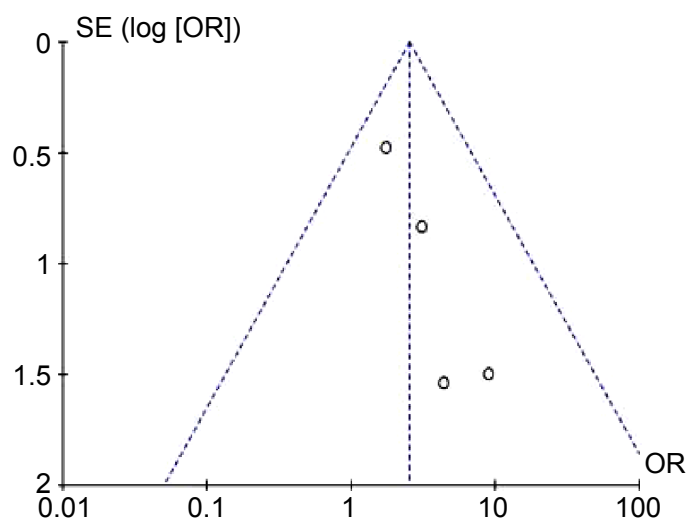

B

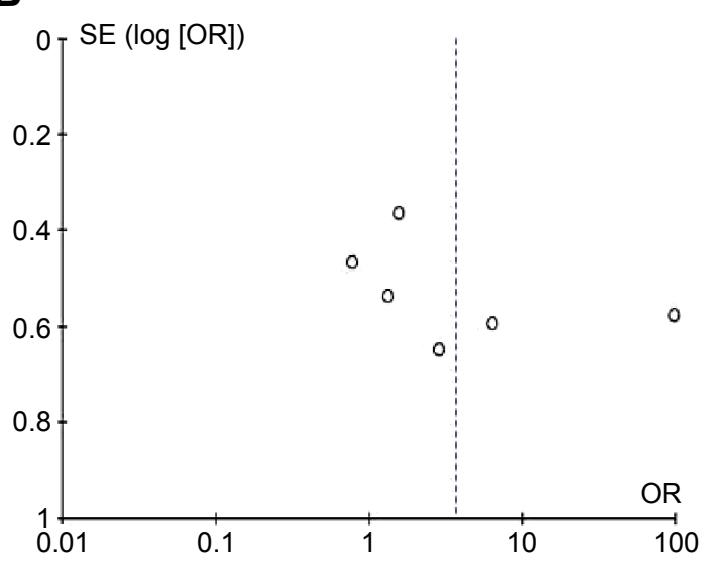

D

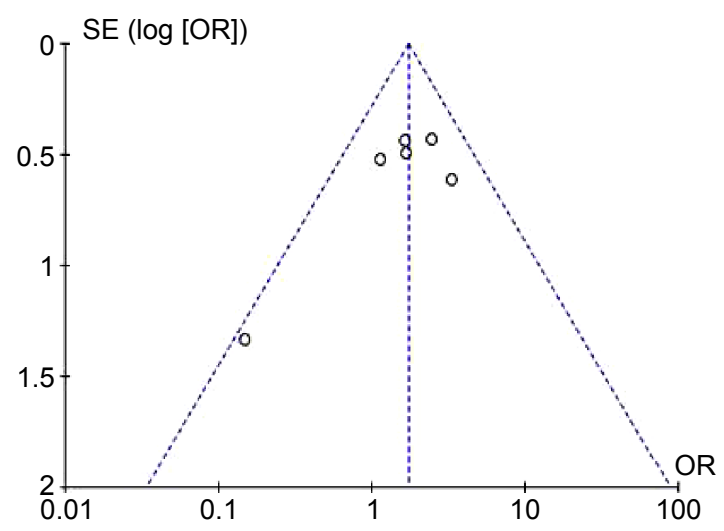

Figure 6 Funnel plot for assessment of publication bias in the meta-analysis.

Notes: (A) Gastric cancer tissues versus normal gastric mucosa. (B) Gastric cancer tissues versus adjacent gastric mucosa. (C) Adjacent gastric mucosa versus normal gastric mucosa. (D) Helicobacter pylori-positive versus -negative.

Abbreviations: OR, odds ratio; SE, standard error. 
in $\mathrm{CDH} 1$ promoter hypermethylation are reversible, drug treatment through demethylation may be useful to delay carcinogenesis and progression. In fact, treatment of CDH1negative tumor cells with the demethylating agent 5-aza2 -deoxycytidine induced re-expression of $C D H 1 \mathrm{mRNA}$ and/or protein in several types of tumor cells including colorectal cancer, ${ }^{28}$ esophageal cancer, ${ }^{29}$ lung cancer, ${ }^{30}$ as well as prostate cancer. ${ }^{31}$ A combination of histone deacetylase inhibitors and DNA methyltransferase inhibitors suppresses the growth of endometrial cancer, which is likely mediated by upregulation of $\mathrm{CDH} 1$ and downregulation of $\mathrm{Bcl}-2 .{ }^{32}$ Transfection of CDH1 cDNA into R-HepG2 cells, in which $\mathrm{CDH} 1$ promoter was hypermethylated in drug resistance of a doxorubicin-induced multidrug-resistant hepatocellular carcinoma cell line, led to increased amount of doxorubicin uptake, decreased cell viability, decreased P-glycoprotein expression, and increased apoptotic population of cells exposed to doxorubicin. ${ }^{33}$ In addition, $1 \alpha, 25(\mathrm{OH})(2) \mathrm{D}(3)$ promoted differentiation of breast cancer MDA-MB-231 cells by inducing de novo E-cadherin expression, an effect that was time- and dose-dependent. ${ }^{34}$ Therefore, this kind of approach targeting CDH1 may bring new directions and hope for cancer treatment through gene-targeted therapy.

$C D H 1$, as a tumor suppressor gene, functionally keeps cell-cell adhesion and controls epithelial cell arrangement in normal order and layer. An in vitro study demonstrated that loss of the expression or function of $C D H 1$ can initiate the activation of transcription factors which are associated with epithelial-mesenchymal transition, finally leading to cancer cell metastasis. ${ }^{35}$ To better understand the correlation between CDH1 methylation and $\mathrm{GC}$, comprehensive evaluation on the methylation makers in GC should be further addressed. Although a large number of studies have demonstrated the potential relationship between $C D H 1$ methylation and GC, a meta-analysis can summarize the studies and compare different subgroup characters.

Consistent results were shown in sensitivity analyses, and no evidence of publication bias was found. This study has several potential limitations. First, the possibility of information and selection biases and unidentified confounders could not be completely excluded because all of the included studies were observational. Second, the search strategy was restricted to articles published in English. Articles with potentially high-quality data that were published in other languages were not included because of anticipated difficulties in obtaining accurate medical translation. Most selected publications were from Asia, hence caution should be taken when our findings are interpreted among general populations. In addition, there are high heterogeneities in the data of
Figures 2 and $3, I^{2}$ test was $>50 \%$, thus we used a random effects model to pool data. Data heterogeneity may come from tissue sample preparation, DNA isolation condition, polymerase chain reaction condition, etc.

\section{Conclusion}

In summary, $C D H 1$ promoter hypermethylation is associated with $\mathrm{GC}$ risk based on the meta-analysis, which indicates that CDH1 hypermethylation might be a biomarker of GC, with potential value as a drug candidate for the therapy of GC patients. In addition, further large-scale studies, especially multicenter and well-matched cohort research, will provide more insight into the role of $\mathrm{CDH} 1$ in the carcinogenesis and clinical implementation of GC patients.

\section{Disclosure}

The authors report no conflicts of interest in this work.

\section{References}

1. Jemal A, Bray F, Center MM, Ferlay J, Ward E, Forman D. Global cancer statistics. CA Cancer J Clin. 2011;61:69-90.

2. Yang W, Raufi A, Klempner SJ. Targeted therapy for gastric cancer: molecular pathways and ongoing investigations. Biochim Biophys Acta. 2014; 1846:232-237.

3. GASTRIC (Global Advanced/Adjuvant Stomach Tumor Research International Collaboration) Group; Oba K, Paoletti X, et al. Role of chemotherapy for advanced/recurrent gastric cancer: an individualpatient-data meta-analysis. Eur J Cancer. 2013;49:1565-1577.

4. Ghavifekr Fakhr M, Farshdousti Hagh M, Shanehbandi D, Baradaran B. DNA methylation pattern as important epigenetic criterion in cancer. Genet Res Int. 2013;2013:317569.

5. Delpu Y, Cordelier P, Cho WC, Torrisani J. DNA methylation and cancer diagnosis. Int J Mol Sci. 2013;14:15029-15058.

6. Ma X, Wang YW, Zhang MQ, Gazdar AF. DNA methylation data analysis and its application to cancer research. Epigenomics. 2013;5:301-316.

7. Otani K, Li X, Arakawa T, Chan FK, Yu J. Epigenetic-mediated tumor suppressor genes as diagnostic or prognostic biomarkers in gastric cancer. Expert Rev Mol Diagn. 2013;13:445-455.

8. Sapari NS, Loh M, Vaithilingam A, Soong R. Clinical potential of DNA methylation in gastric cancer: a meta-analysis. PLoS One. 2012;7:e36275.

9. Bussemakers MJ, van Bokhoven A, Mees SG, Kemler R, Schalken JA. Molecular cloning and characterization of the human E-cadherin cDNA. Mol Biol Rep. 1993;17:123-128.

10. van Roy F. Beyond E-cadherin: roles of other cadherin superfamily members in cancer. Nat Rev Cancer. 2014;14:121-134.

11. Takeichi M. Cadherins: a molecular family important in selective cellcell adhesion. Аnпи Rev Biochem. 1990;59:237-252.

12. Karayiannakis AJ, Syrigos KN, Chatzigianni E, et al. Aberrant E-cadherin expression associated with loss of differentiation and advanced stage in human pancreatic cancer. Anticancer Res. 1998;18: 4177-4180.

13. Zheng Z, Pan J, Chu B, Wong YC, Cheung AL, Tsao SW. Downregulation and abnormal expression of E-cadherin and beta-catenin in nasopharyngeal carcinoma: close association with advanced disease stage and lymph node metastasis. Hum Pathol. 1999;30: $458-466$.

14. Oka H, Shiozaki H, Kobayashi K, et al. Expression of E-cadherin cell adhesion molecules in human breast cancer tissues and its relationship to metastasis. Cancer Res. 1993;53:1696-1701. 
15. Humar B, Blair V, Charlton A, More H, Martin I, Guilford P. E-cadherin deficiency initiates gastric signet-ring cell carcinoma in mice and man. Cancer Res. 2009;69:2050-2056.

16. Oliveira C, Sousa S, Pinheiro H, et al. Quantification of epigenetic and genetic 2nd hits in $\mathrm{CDH} 1$ during hereditary diffuse gastric cancer syndrome progression. Gastroenterology. 2009;136:2137-2148.

17. Altman DG, McShane LM, Sauerbrei W, Taube SE. Reporting recommendations for tumor marker prognostic studies (REMARK): explanation and elaboration. BMC Med. 2012;10:51.

18. Sculier JP, Ghisdal L, Berghmans T, et al; European Lung Cancer Working Party. The role of mitomycin in the treatment of non-small cell lung cancer: a systematic review with meta-analysis of the literature. Br J Cancer. 2001;84:1150-1155.

19. Shao D, He S. [Meta-analysis of clinical randomized controlled trials comparing refractive with diffractive multifocal intraocular lenses in cataract surgery]. Zhonghua Yan Ke Za Zhi. 2014;50:109-120. Chinese.

20. Higgins JP, Thompson SG, Deeks JJ, Altman DG. Measuring inconsistency in meta-analyses. BMJ. 2003;327:557-560.

21. DerSimonian R. Meta-analysis in the design and monitoring of clinical trials. Stat Med. 1996;15:1237-1248; discussion 1249-1252.

22. Begg CB, Mazumdar M. Operating characteristics of a rank correlation test for publication bias. Biometrics. 1994;50:1088-1101.

23. Matsusaka K, Funata S, Fukayama M, Kaneda A. DNA methylation in gastric cancer, related to Helicobacter pylori and Epstein-Barr virus. World J Gastroenterol. 2014;20:3916-3926.

24. Shin CM, Kim N, Lee HS, et al. Changes in aberrant DNA methylation after Helicobacter pylori eradication: a long-term follow-up study. Int J Cancer. 2013;133:2034-2042.

25. Su CY, Li YS, Han Y, Zhou SJ, Liu ZD. Correlation between expression of cell adhesion molecules $\mathrm{CD}_{44} \mathrm{v} 6$ and E-cadherin and lymphatic metastasis in non-small cell lung cancer. Asian Pac J Cancer Prev. 2014; 15:2221-2224

26. Ponce E, Louie MC, Sevigny MB. Acute and chronic cadmium exposure promotes E-cadherin degradation in MCF7 breast cancer cells. Mol Carcinog. Epub 2014 May 5.

27. Schildberg CW, Abba M, Merkel S, et al. Gastric cancer patients less than 50 years of age exhibit significant downregulation of E-cadherin and CDX2 compared to older reference populations. Adv Med Sci. 2014;59:142-146.

28. Liu Y, Hong Y, Zhao Y, Ismail TM, Wong Y, Eu KW. Histone H3 (lys-9) deacetylation is associated with transcriptional silencing of E-cadherin in colorectal cancer cell lines. Cancer Invest. 2008;26:575-582.

29. Ling ZQ, Li P, Ge MH, et al. Hypermethylation-modulated downregulation of $\mathrm{CDH} 1$ expression contributes to the progression of esophageal cancer. Int J Mol Med. 2011;27:625-635.

30. Liu YY, Han JY, Lin SC, Liu ZY, Jiang WT. Effect of CDH1 gene methylation on transforming growth factor (TGF- $\beta$ )-induced epithelialmesenchymal transition in alveolar epithelial cell line A549. Genet Mol

31. Patra A, Deb M, Dahiya R, Patra SK. 5-Aza-2'-deoxycytidine stress response and apoptosis in prostate cancer. Clin Epigenetics. 2011;2: 339-348.

32. Yi TZ, Li J, Han X, et al. DNMT inhibitors and HDAC inhibitors regulate E-cadherin and Bcl-2 expression in endometrial carcinoma in vitro and in vivo. Chemotherapy. 2012;58:19-29. Res. 2014;13:8568-8576.

33. Jiang L, Chan JY, Fung KP. Epigenetic loss of CDH1 correlates with multidrug resistance in human hepatocellular carcinoma cells. Biochem Biophys Res Commun. 2012;422:739-744.

34. Lopes N, Carvalho J, Durães C, et al. 1Alpha, 25-dihydroxyvitamin D3 induces de novo E-cadherin expression in triple-negative breast cancer cells by CDH1-promoter demethylation. Anticancer Res. 2012;32:249-257.

35. Machado JC, Oliveira C, Carvalho R, et al. E-cadherin gene (CDH1) promoter methylation as the second hit in sporadic diffuse gastric carcinoma. Oncogene. 2001;20:1525-1528.

36. Oh JH, Rhyu MG, Jung SH, Choi SW, Kim SI, Hong SJ. Slow overmethylation of housekeeping genes in the body mucosa is associated with the risk for gastric cancer. Cancer Prev Res (Phila). 2014;7:585-595.

37. Lee KH, Hwang D, Kang KY, et al. Frequent promoter methylation of CDH1 in non-neoplastic mucosa of sporadic diffuse gastric cancer. Anticancer Res. 2013;33:3765-3774.

38. Li XJ, Zhao Y, Ren H. [E-cadherin expression and CDH1 promoter methylation in sporadic and hereditary gastric cancer]. Nan Fang $Y_{i}$ Ke Da Xue Xue Bao. 2013;33:125-127. Chinese.

39. Yu QM, Wang XB, Luo J, et al. CDH1 methylation in preoperative peritoneal washes is an independent prognostic factor for gastric cancer. J Surg Oncol. 2012;106:765-771.

40. Ben Ayed-Guerfali D, Benhaj K, Khabir A, et al. Hypermethylation of tumor-related genes in Tunisian patients with gastric carcinoma: clinical and biological significance. J Surg Oncol. 2011;103:687-694.

41. Borges Bdo N, Santos Eda S, Bastos CE, et al. Promoter polymorphisms and methylation of E-cadherin (CDH1) and KIT in gastric cancer patients from northern Brazil. Anticancer Res. 2010;30:2225-2233.

42. Tahara T, Shibata T, Arisawa T, et al. CpG island promoter methylation (CIHM) status of tumor suppressor genes correlates with morphological appearances of gastric cancer. Anticancer Res. 2010;30:239-244.

43. Ferrasi AC, Pinheiro NA, Rabenhorst SH, et al. Helicobacter pylori and EBV in gastric carcinomas: methylation status and microsatellite instability. World J Gastroenterol. 2010;16:312-319.

44. Kim JH, Jung EJ, Lee HS, Kim MA, Kim WH. Comparative analysis of DNA methylation between primary and metastatic gastric carcinoma. Oncol Rep. 2009;21:1251-1259.

45. Zhang KL, Sun Y, Li Y, et al. Increased frequency of $\mathrm{CpG}$ island methylator phenotype and $\mathrm{CDH} 1$ methylation in a gastric cancer highrisk region of china. Transl Oncol. 2008;1:28-35.

46. Leal M, Lima E, Silva P, et al. Promoter hypermethylation of CDH1, FHIT, MTAP and PLAGL1 in gastric adenocarcinoma in individuals from Northern Brazil. World J Gastroenterol. 2007;13:2568-2574.

47. Oue N, Mitani Y, Motoshita J, et al. Accumulation of DNA methylation is associated with tumor stage in gastric cancer. Cancer. 2006;106:1250-1259.

48. Liu YC, Shen CY, Wu HS, et al. Helicobacter pylori infection in relation to E-cadherin gene promoter polymorphism and hypermethylation in sporadic gastric carcinomas. World $J$ Gastroenterol. 2005;11:5174-5179.

49. Graziano F, Arduini F, Ruzzo A, et al. Combined analysis of E-cadherin gene $(\mathrm{CDH} 1)$ promoter hypermethylation and E-cadherin protein expression in patients with gastric cancer: implications for treatment with demethylating drugs. Ann Oncol. 2004;15:489-492.

Drug Design, Development and Therapy

\section{Publish your work in this journal}

Drug Design, Development and Therapy is an international, peerreviewed open-access journal that spans the spectrum of drug design and development through to clinical applications. Clinical outcomes, patient safety, and programs for the development and effective, safe, and sustained use of medicines are a feature of the journal, which

\section{Dovepress}

has also been accepted for indexing on PubMed Central. The manuscript management system is completely online and includes a very quick and fair peer-review system, which is all easy to use. Visit http://www.dovepress.com/testimonials.php to read real quotes from published authors. 